\title{
Management of a polytrauma in the maritime environment
}

\author{
Cécile Montocchio-Buadès ${ }^{1}$, Maëlle Daurat ${ }^{1}$, Macha Ducombs ${ }^{2}$, Charles-Edouard Vallet ${ }^{2}$ \\ ${ }^{1}$ Université de Bretagne Occidentale, Brest, France \\ ${ }^{2}$ French Navy
}

\begin{abstract}
Background: A polytraumatised person is a severely injured patient with an association of several injuries including at least one life-threatening. In an isolated and hostile environment like the maritime environment, the principles of early care and fast evacuation of a polytraumatised person are sometimes difficult to apply.

Clinical case: We report the story of a patient with a bilateral fracture of the lower extremities following an accident on board a Moldavian tugboat off the coasts of Djibouti. He received a medical treatment thanks to the intervention of a French military frigate after receiving a message of assistance by very high frequency, and then a helicopter evacuation to the Medicine and Surgery "Bouffard" Hospital. The pre-hospital care of a polytraumatised patients with limb injuries and the specificities of an intervention in a maritime environment are described. The maritime international conventions relating to rescue at sea as well as the specificities of the management of an injured person on a ship sailing under the Moldavian flag are explained. Emphasis is placed on the importance of watchkeeping at sea and the presence on board of trained first-aid personnel. Finally, a point is made on the French organisation of health support for ships, through the Maritime Medical Consultation Centre and the Regional Operational Centres for Surveillance and Rescue.

Conclusions: This case illustrates that the solidarity of the seafarers allows a seriously wounded person to maintain, despite a degraded and isolated situation, the chances of successful management and preserve the functional prognosis.
\end{abstract}

(Int Marit Health 2018; 69, 2: 126-128)

Key words: polytrauma, maritime conventions, Search and Rescue

\section{INTRODUCTION}

The definition of polytraumatised person is a severely injured patient with two or more severe injuries in at least two or more areas of the body [1].

The time factor is fundamental for the treatment. The management and evaluation of the severity of multiple trauma patients must be early, fast and of high quality. That conditions the prognosis [2].

In an isolated and hostile environment like in the maritime area [3], these principles of precocity are sometimes difficult to apply: uneasy access to the patient, long transit times, lack of available resources [4]. However, Internation- al Maritime Organisation Circular 960 of June $20^{\text {th }}, 2000$ requires trying to provide seafarers with medical care as nearly as possible equivalent to the care they would receive ashore [5].

The management of a polytrauma patient on board a tugboat will be introduced here.

\section{CLINICAL CASE}

In January 2015 on a Moldovian registered tugboat, a 26-year-old male Indian seafarer sustained severe injuries of both lower legs when a tensioned wire broke and swept across the deck. There was no medical staff or medical

Dr. Cécile Montocchio-Buadès, Université de Bretagne Occidentale, 22, rue Camille Desmoulins, 29200 Brest, France, e-mail: cecile.montocchio@laposte.net 
equipment aboard. An open leg wound was packed with cotton towels to control bleeding. No disinfection was attempted. Both lower limbs were immobilised with wooden strips.

Eleven hours after the accident, at 17:00 hours, a military ship off the Horn of Africa (about 100 nautical miles from the Djiboutian coast) responded to a distress call by very high frequency radio from the tugboat and got a doctor and a nurse on board 6 hours later.

They found the seafarer conscious (Glasgow 15), with tachycardia at $120 \mathrm{bpm}$, a low blood pressure at $87 / 58$ $\mathrm{mmHg}$, and a pain assessed at 8/10. After removing the makeshift splints, there was clinically an open, moderately displaced diaphyseal fracture (Cauchoix 2) of the right tibia, a suspected closed diaphyseal fracture of the left tibia and a deep wound of the left calf. Both clinical diagnoses were later confirmed.

Initial treatment on the tug included intravenous normal saline solution, morphine (titration) and amoxicillin - clavulanic acid. The left wound was closed with 2.0 sutures with prior disinfection and a left leg splint was applied on site. The right open fracture wound was disinfected and when no signs of arterial bleeding were found, a compression bandage was applied. The fracture was tentatively reduced and splinted under Ketamine + Midazolam anaesthesia.

After 1.5 hours the patient was winched in a Transaco stretcher aboard the frigate helicopter and transferred directly from the tug via an air base to "Bouffard" Hospital in Djibouti. There, he was treated with right-sided external fixation and a left tibial nail.

\section{DISCUSSION}

To begin, this clinical case concerns us about the 11 hours elapsed before the detection of the distress message of the tug by a boat. Indeed, it is surprising that during all this time, no ship intercepted the message and came to help the tug.

However, the Brussels Conventions of September $23^{\text {th }}$, 1910 [6], the SOLAS International Convention of January $26^{\text {th }}, 1914$ [7], and the Montego Bay Convention [8] define rescue as an obligation incumbent on the master of the ship. They state that it is "bound, that the dangers of his vessel, his crew and his passengers allow it, to assist any person to the sea (...) on the verge of being lost". The Montego Bay Convention, corroborated by the SOLAS Convention, also provides for coastal states to participate in the rescue through the establishment of a rescue service. This includes the establishment of communication means, detection, and the rescue equipment implementation. Finally, the Search and Rescue (SAR) Convention [9], which deals specifically with rescue operations at sea, also indicates that States must provide first aid to shipwrecked persons and secure them in a safe environment [10].
Moreover, the lack of regulation by a Maritime Telemedical Assistance Services (TMAS) is surprising. Is it related to a lack of knowledge if the procedures by the tug commander?

Indeed, in coordination with the local Maritime Rescue Coordination Centre (MRCC), TMAS organisations arrange for medevac to shore, emergency treatment at land facilities and the dispatch of medical personnel to ships with ill mariners. TMAS is also a medical advice service for seafarers that can provide distant assistance and support through maritime radio, e-mail, telephone of fax. The rationale for TMAS services is that medical emergencies can occur while many days away from harbour and at prohibitively large distances from SAR bases, making immediate evacuation impractical or impossible. TMAS specialists diagnose cases using non-expert symptom descriptions and advise untrained personnel about emergency treatment given the available supplies and facilities. All seafaring nations are required by International Labour Organisation/International Maritime Organisation Convention 163 of 1986 to set up a TMAS centre that operates 24 hours a day. The centre must be staffed by physicians trained in remote consultation and in the peculiarities of shipboard treatment to all civilian ships within their SAR region [11].

To continue, it is interesting to ask the question of the lack of first aid provided to the injured before the arrival of the French medical team. Indeed, boats sailing under the Moldavian flag, as in this case, are subject to Moldavian national legislation and international conventions ratified by the Moldavian State. This state has a specialised central authority in the protection of human life at sea. Within the framework of the certification of the equipment and the crew of the ship, the boat must have a medical file and at least one seaman on board must have first aid training. Either way, the commander is responsible for the health of his crew. In the event of a pathology occurring at sea, the evacuation of the patient is at the expense of the ship-owner [12]. However, nothing is specified in the Moldavian legislation concerning the minimum medical equipment to be on board... In the reported case, the crew apparently had nothing. So the priority was to evacuate the patient, which was possible thanks to the very high frequency emergency call and the presence of a helicopter on the French military frigate.

If the decision to evacuate was fast, a 1 hour and 30 minutes boarding delay was still necessary to assess the lesions, do the simple cleaning and suturing of the wounds, infuse, balance and relieve the patient. Indeed, in massive external bleeding, the priority is to stop the bleeding by direct pressure and limb elevation, recommended at first. If this does not work, a tourniquet must be used, and the transfer as fast as possible to the hospital is rec- 
ommended. Sometimes the best way to control a bleeding is to reduce and immobilise the fracture. Vital parameters should be monitored continuously because of the high risk of haemorrhagic shock. The goal is to maintain a tension between $80 \mathrm{mmHg}$ and $120 \mathrm{mmHg}$ [13]. Do not hesitate to take pictures or drawings of the initial pathology before transfer to the hospital. In case of neurovascular deficit, the realignment must be immediate, under a good analgesia. For initial analgesia, morphine titration is often the easiest and fastest. Entonox can also be used, as well as ketamine $0.5 \mathrm{mg} / \mathrm{kg}$. In second line, according to the time available and the kind of injuries, femoral block is an interesting alternative [13]. Any orthopaedic open trauma should be treated by cleansing and protecting the wound, intravenous antibiotics and immobilisation [14].

Finally, the perfect time does not exist; the best is always as quickly as possible, optimally within 24 hours. This meeting deadline on a ship at sea is possible only with the presence of a person with medical training and proper equipment on board.

Thus, the tug reporting difficulties of propulsion not allowing him to join Djibouti that more than 24 hours later, a helicopter evacuation of 40 minutes was privileged. In addition, it was easier to condition the patient for a direct transfer by helicopter to the hospital than to make a first winch to the frigate then a second flight to the hospital. The weather conditions and the hourly availability of the helicopter influenced this decision. The patient was therefore conditioned at best for winching, with immobilisation of the two lower limbs, one with a plastered posterior gutter made on the tug.

\section{CONCLUSIONS}

This clinical case recalls that the risks of a seafarer's life include daily traumas at sea as well as isolation. The pres- ence of a first aid trained staff equipped with a minimum of an emergency kit on board takes all its importance. Moreover, this case illustrates that the solidarity between seafarers allows the good management of a seriously wounded person and the preservation of the functional prognosis despite a degraded situation.

\section{REFERENCES}

1. Kroupa J. Definition of " polytrauma " and " polytraumatism ". Acta Chir Orthop Traumatol Cech. 1990; 57(4): 347-360.

2. Stahel P, Heyde C, Ertel W. Current Concepts of Polytrauma Management. Eur JTrauma. 2005; 31(3): 200-211, doi:10.1007/s00068-005-2028-6.

3. Maritime Transportation Research Board, Commission on Sociotechnical Systems, National Research Council. 1979.

4. Napoleone P. Accidents on board merchant ships. Suggestions based on Centro Internazionale Radio Medico (CIRM) experience. Int Marit Health. 2016; 67(1): 21-23, doi: 10.5603/IMH.2016.0005, indexed in Pubmed: 27029925.

5. Department of Economic Development. Medical care onboard ship and ashore. Maritime Labour Notice.

6. Admiralty and Maritime Law Guide, International Conventions. Convention for the Unification of Certain Rules of Law with respect to Collisions between Vessels. 1910.

7. International conference on safety of life at sea. Text of the convention for the safety of life at sea. London, 1914.

8. Armateurs de France. La convention de Montego Bay en 50 leçons.

9. International Convention on Maritime Search and Rescue (SAR). avr 27. 1979.

10. International Maritime Organization. Medical Assistance at Sea. MSC/Circ. 960 juin, 2000.

11. International Maritime Organization. Adoption of amendments to the international aeronautical and maritime search and rescue (IAMSAR) manual. MSC.1/Circ. 1289 déc, 2008.

12. Maritime code of the Republic of Moldova. sept 30. 1999.

13. Lee C, Porter KM. Prehospital management of lower limb fractures. Emerg Med J. 2005; 22(9): 660-663, doi: 10.1136/ emj.2005.024489, indexed in Pubmed: 16113195.

14. Gosselin RA, Roberts I, Gillespie WJ. Antibiotics for preventing infection in open limb fractures. Cochrane Database Syst Rev. 2004(1): CD003764, doi: 10.1002/14651858.CD003764.pub2, indexed in Pubmed: 14974035. 